\title{
MAGNETIC PROPERTIES OF THE Fe-Ni AND Fe-Ni-Mo SOFT MAGNETIC MATERIALS PREPARED BY THE MECHANICAL MILLING AND WARM CONSOLIDATION
}

\author{
Denisa OLEKŠÁKOVÁ*, Ján FÜZER ${ }^{* *}$, Peter KOLLÁR ${ }^{* *}$ \\ *Department of Applied Mathematics and Informatics, Faculty of Engineering, \\ Technical University of Košice, Letná 9, 04200 Košice, Slovak Republic, tel. +421 55602 2227, e-mail: denisa.oleksakova@tuke.sk \\ *** Institute of Physics, Faculty of Science, P. J. Šafárik University of Košice, Park Angelinum 9, 04023 Košice, Slovak Republic
}

\begin{abstract}
The aim of the present work was to study the influence of mechanical milling and subsequently the compacting on the structure and the soft magnetic properties of NiFe (81 wt. \% of Ni) and NiFeMo (79 wt. \% of Ni, $19 \mathrm{wt}$. \% of Fe) alloys. We have investigated the influence of powder size on AC and DC magnetic properties of the bulk samples prepared by hot compaction.
\end{abstract}

Keywords: soft magnetic material, mechanical milling, compaction, permalloy

\section{INTRODUCTION}

Permalloy is the name which has been given to a series of nickel-iron alloys so heat-treated to have an initial permeability much larger than that of pure iron and are produced usually in the form of thin sheet (ring prepared by the wound ribbons or laminated thin sheets) [1].

Therefore it is logical to attempt to prepare such material direct in required form (more "bulk" form), for example in the form of a cylinder or a ring, which would be more convenient for some industrial applications.

Over the past several years the method of mechanical milling and mechanical alloying was widely spread in order to exploit it to produce a variety of equilibrium and non-equilibrium alloy phases and possesses further possibility for research work and application of permalloy. The advantage of this process technology is that the powder can be produced in large quantities and the processing parameters can be easily controlled [2]. One of the methods how to prepare material in bulk is to compact the powder. The aim of this work was to investigate the influence of powder size of Ni-based alloys of the bulk samples prepared by hot compaction on AC and DC magnetic properties.

The Ni-Fe based alloy (permalloy) system shows excellent soft magnetic properties and these alloys have been widely applied in the field of electronic devices and industry.

The aim of this work was to investigate the structure and magnetic properties of $\mathrm{Ni}_{81} \mathrm{Fe}_{19}$ (wt. \%) and $\mathrm{Ni}_{79} \mathrm{Fe}_{16} \mathrm{Mo}_{5}$ (wt. \%) alloys and the contribution of the components of the core losses of bulk soft magnetic materials prepared by the compaction of alloy powder obtained by high-energy milling of the Ni-Fe ribbon.

\section{SUBJECT}

The soft magnetic properties of permalloy would change with $\mathrm{Ni}$ content: lower coercive field (about 80 at. \% Ni), higher saturation magnetic induction (about 50 at. \% Ni) and lower permeability but higher electrical resistance (about 35 at. \% Ni) [3]. In [4] the effect of molybdenum alloying additions on the milling behaviour and subsequently on the magnetic properties was studied. It was found that molybdenum has a strong effect on the crystallization behaviour and NiFeMo alloys have very high relative permeability and low eddy current losses.

\section{METHODS}

We have prepared two types of powder samples (Fig. 1). The sample A was prepared by mechanical milling of microcrystalline ribbon $\mathrm{NiFe}$ (81 wt. \% of $\mathrm{Ni}$ ) obtained by melt-spinning. The ribbon is a good shape for milling. To prepare sample B, swarfs of NiFeMo (79 wt. \% of Ni, 16 wt. \% of Fe) were milled, which were prepared from the ingot by turning. We used swarfs, because it was not possible to prepare ribbons with this chemical composition. The milling of sample A and B was performed in protective argon atmosphere and in liquid nitrogen respectively in a high-energy planetary ball mill (RETSCH PM4000 with hardened steel vials and balls) with ball-to-powder-ratio of 6:1 and with a speed of $180 \mathrm{rpm}$.

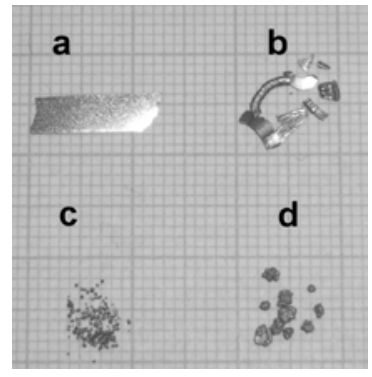

Fig. 1 Ribbon NiFe (a), powder prepared by milling of ribbon NiFe (c), swarfs NiFeMo (b), and powder prepared by milling of swarfs NiFeMo (d)

The bulk samples (Fig. 2) were prepared by uniaxial compaction of small pieces of broken ribbon (swarfs) with area of several $\mathrm{mm}^{2}$ respectively of powders in the form of cylinders (diameter $10 \mathrm{~mm}$, height $2.5 \mathrm{~mm}$, weight approx. $2 \mathrm{~g}$ ). The compaction was performed at a pressure of $800 \mathrm{MPa}$ for $5 \mathrm{~min}$ at $600{ }^{\circ} \mathrm{C}$ in vacuum of $5 \times 10^{-3} \mathrm{~Pa}$ (in order to prevent oxidation and to remove free gases 
from powder before the compaction). The cylinders were annealed at temperatures between $500{ }^{\circ} \mathrm{C}$ and $1200{ }^{\circ} \mathrm{C}$ for 1 hour.

In order to prepare ring-shaped samples more suitable for AC and DC measurements, the cylinders of bulk samples were drilled using spark plasma erosion (the diameter is $5 \mathrm{~mm}, 10$ primary turns, 20 secondary turns).

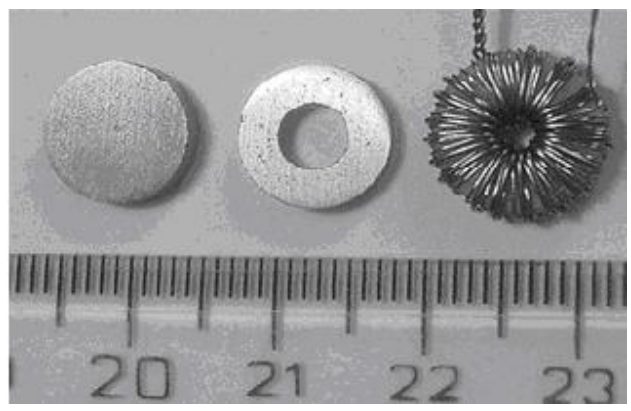

Fig. 2 Bulk samples $\mathrm{Ni}_{81} \mathrm{Fe}_{19}$ (wt.\%) prepared for ac and dc measurements

\section{RESULTS}

\subsection{Structure and morphology}

The crystalline character of all samples (bulk, powder, $\mathrm{NiFe}, \mathrm{NiFeMo}$ ) was confirmed by X-ray diffraction with Fe filtered Co-K $\alpha$ radiation (Philips PW 1050) with diffracted beam graphite monochromator [5] and differential scanning calorimeter (NETZSCH DSC 404), as we can see in Fig. 3 for sample NiFe and in Fig. 4 for sample NiFeMo. The reason for the different heat flow (Fig. 3) is the increasing of the energy, which was accumulated by the milling and then it released.

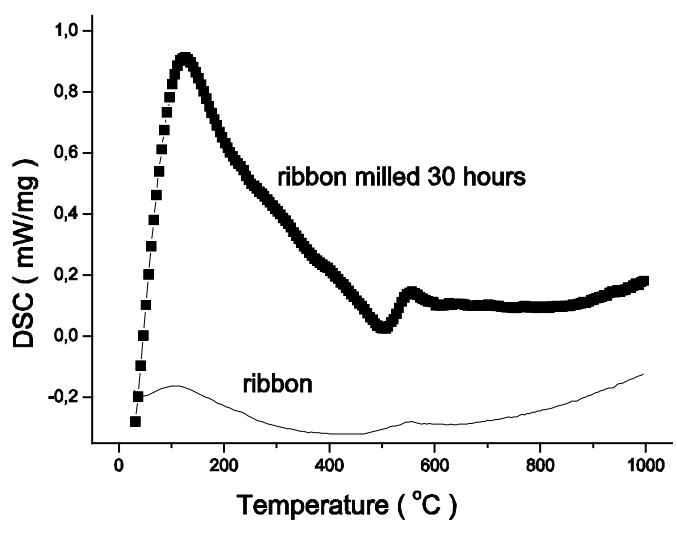

Fig. 3 DSC plots of samples $\mathrm{Ni}_{81} \mathrm{Fe}_{19}$

The $\mathrm{FeNi}_{3}$ phase $\left(T_{\mathrm{C}}=550^{\circ} \mathrm{C}\right)$ was created as major phase for Ni-Fe sample. The mechanical milling of $\mathrm{Ni}-$ $\mathrm{Fe}-\mathrm{Mo}$ alloy causes the creation $\mathrm{FeNi}_{3}$ phase and minor phase with higher content of Fe with $T_{\mathrm{C}}=650{ }^{\circ} \mathrm{C}$ [5].

The powder morphology and the morphology of the bulk samples were studied by scanning electron microscopy (Vega 5135 Tescan).

The morphology of the surface of the Ni-Fe ribbon in as-quenched state is depicted in Fig. 5a. Small pieces of the ribbon with area of several $\mathrm{mm}^{2}$ were compacted, Fig. 5d. The ribbon pieces were brittle enough to be crushed during compaction process and the average linear size of the pieces was reduced to $5 \mu \mathrm{m}$. The 5 hours milled ribbon, consisting of powder elements with relatively sharp edges with size of about $30 \mu \mathrm{m}$ (Fig. 5b), was precursor of the compacted bulk created by $3 \mu \mathrm{m}$ elements, Fig. 5e. The powder milled for 30 hours had average size about $10 \mu \mathrm{m}$ (Fig. 5c) and the surface of the bulk prepared from this powder is very smooth and no pores are visible, Fig. 5f [6].

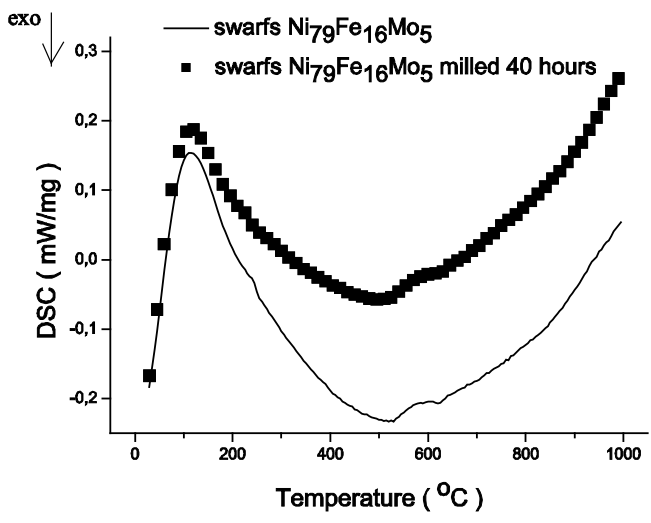

Fig. 4 DSC plots of samples $\mathrm{Ni}_{79} \mathrm{Fe}_{16} \mathrm{Mo}_{5}$

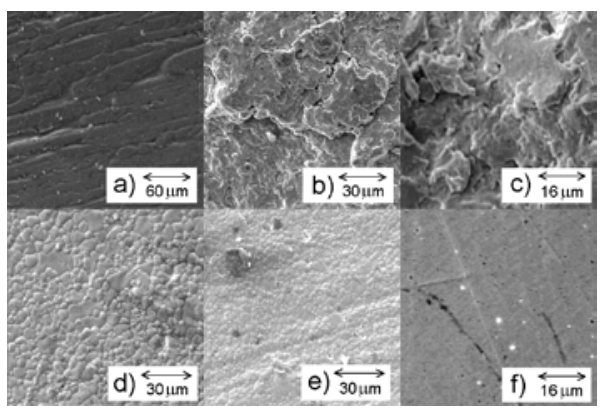

Fig. 5 The morphology a) of the Ni-Fe ribbon's surface, b) of the $5 \mathrm{~h}$ and c) of the $30 \mathrm{~h}$ milled powder, d) of the compact prepared of broken ribbon, e) of the compact prepared from $5 \mathrm{~h}$ milled powder and f) of the compact prepared from $30 \mathrm{~h}$ milled powder

\subsection{Coercivity}

The coercivity of the bulk samples was measured by a Forster Koerzimat at room temperature and is presented in Fig. 6 and Fig. $7[6,7]$.

The coercivity of the powder sample increases with milling time and we assume that displacement of the domain walls becomes less and less important magnetization process with milling time and the rotation of magnetization vector becomes more dominant. The magnetization process of the powder material is realized more or less separately for each powder element. The coercivity of the bulk material before heat treatment is lower than that for powder and that is why we can assume that the magnetic "contact"' is restored after compaction. The annealing at higher temperatures causes relaxation of residual stresses introduced during milling and compaction and improves contact between powder particles, causing lowering of the coercivity. The lowest coercivity of $11 \mathrm{~A} / \mathrm{m}$ (Fig. 6) was achieved for the sample NiFe prepared by compaction of broken ribbon, annealed 
at $1200{ }^{\circ} \mathrm{C}$, and it is comparable with that for material prepared by convention way in the form of thin sheet $4 \mathrm{~A} / \mathrm{m}[8]$.

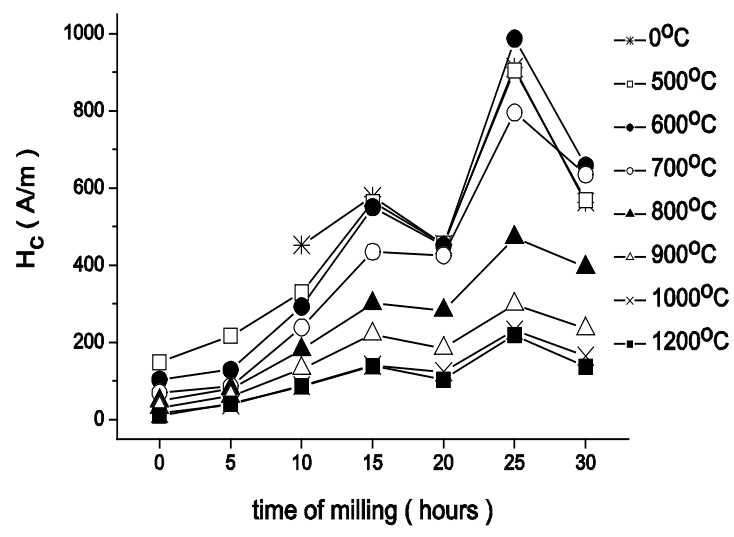

Fig. 6 Coercivity of bulk samples $\mathrm{Ni}_{81} \mathrm{Fe}_{19}$ milled for different time of milling (from 0 to 30 hours) and compacted at temperature to $1200^{\circ} \mathrm{C}$

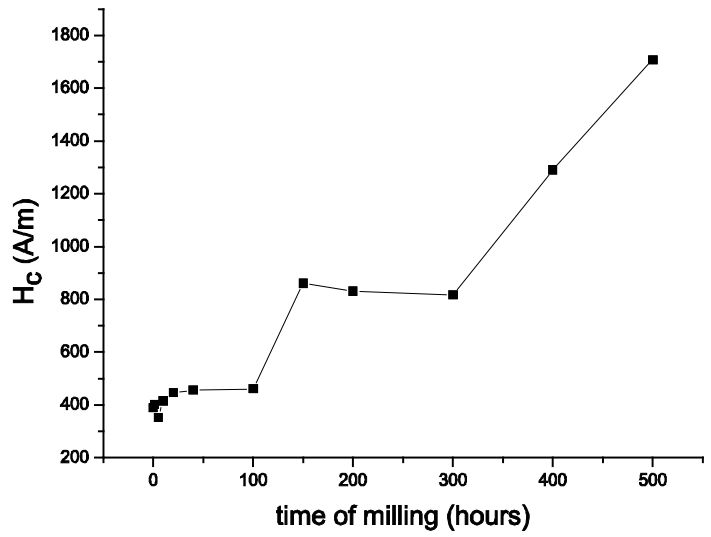

Fig. 7 Coercivity of bulk samples $\mathrm{Ni}_{79} \mathrm{Fe}_{16} \mathrm{Mo}_{5}$ milled for different time of milling (from 0 to 550 hours)

\subsection{Core losses}

The losses were obtained from the ac hysteresis loops measured by a fluxmeter-based hysteresisgraph with sinusoidal flux density time and by the dc hysteresis loops. Peak permeability was determinated from B-H curves.

The core losses $W$ (in $\mathrm{J} / \mathrm{m}^{3}$ ) in the magnetic cores can be divided into three components: hysteresis loss $W_{\mathrm{h}}$, classical eddy current losses $W_{\mathrm{e}}$ and anomalous losses $W_{\mathrm{a}}$ [9]

$W_{t}=W_{h}+W_{e}+W_{a}$

Hysteresis losses $W_{\mathrm{h}}$ can be experimentally determined as the area of the dc hysteresis loop.

The eddy current losses $W_{\mathrm{e}}$ can be expressed as

$W_{e}=\frac{\pi^{2} B_{\max }^{2} d^{2}}{\beta} \sigma f=C_{e} f$ where $C_{e}$ is a constant in which the material parameters and the parameters of the measurement conditions except for the frequency are associated, $d$ is the thickness of the sample, $B_{\mathrm{m}}$ is the maximum flux density, $f$ is the frequency, $\sigma$ is the conductivity, and $\beta$ is a geometrical coefficient. For a rectangular cross-section perpendicular to the direction of the magnetic flux, the geometrical coefficient is

$$
\beta=\frac{6}{1-0.633\left(\frac{w}{h}\right) \tanh \left(1.58 \frac{h}{w}\right)}
$$

where $w$ is the width and $h$ is the height of the rectangle [9].

The anomalous losses are known to be caused mainly by domain wall branching and bowing. These losses arise from the compensation of inhomogeneous internal counterfields (caused by eddy currents) by an applied magnetic field. The anomalous losses can be expressed as

$$
W_{a}=\frac{8.8 \sqrt{S}\left(B_{\max }\right)^{\frac{3}{2}}}{\rho} \sqrt{G \sigma V_{0}}(f)^{\frac{1}{2}}=C_{a}(f)^{\frac{1}{2}}
$$

where $C_{a}$ is a constant in which are associated the material parameters and the parameters of the measurement conditions except for the frequency, $S$ is the cross section of the material perpendicular to the magnetic flux, $G$ and $V_{0}$ are parameters that depend on the material and the magnetisation.

Fig. 8 and Fig. 9 show the peak permeability and the core losses, as a function of frequency for $\mathrm{Ni}-\mathrm{Fe}-\mathrm{Mo}$ and $\mathrm{Ni}-\mathrm{Fe}$ samples for different values of the flux density $B_{\max }$. The peak permeability is decreased, the core losses is increased.

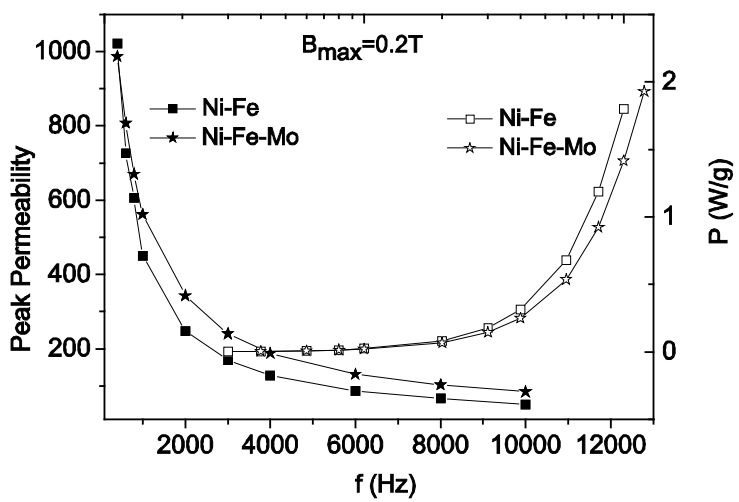

Fig. 8 Frequency dependence of the peak permeability and core losses for Ni-Fe sample and Ni-Fe-Mo sample for $\mathrm{B}_{\max }=0.2 \mathrm{~T}$

Fig. 10 displays the dependence of the AC core losses and the AC coercivity in our bulk samples at a frequency of $20 \mathrm{kHz}$ on the maximum induction, $\mathrm{B}_{\max }$. The core losses increase monotonically with the induction. As can be seen from this figure, the sample $\mathrm{Ni}-\mathrm{Fe}-\mathrm{Mo}$ is characterized by the lowest core losses, which is connected with the presence of Mo element, that slows down the ordering kinetics and lowers the degree of long 
range order thereby increase the resistivity and simplifies the final heat treatment and hence improves the properties [10]. Table 1 compares the DC coercivity, AC core losses, and peak permeability in $\mathrm{Ni}_{81} \mathrm{Fe}_{19}$ bulk sample with $\mathrm{Ni}_{79} \mathrm{Fe}_{16} \mathrm{Mo}_{5}$ bulk sample.

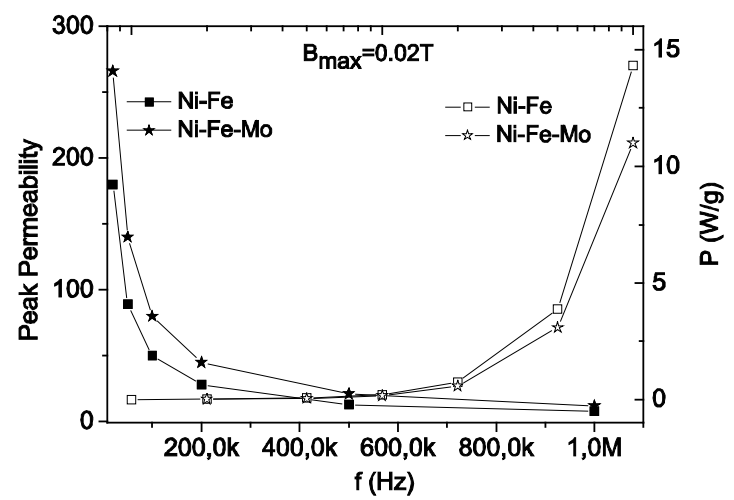

Fig. 9 Frequency dependence of the peak permeability and core losses for Ni-Fe sample and Ni-Fe-Mo sample for $\mathrm{B}_{\max }=0.02 \mathrm{~T}$

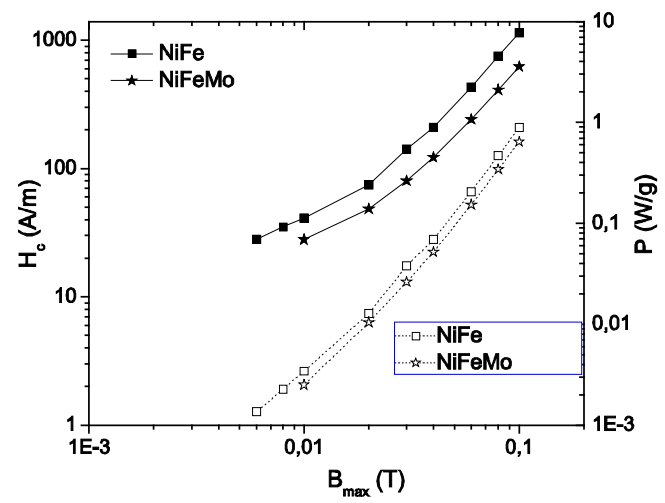

Fig. 10 Coercivity and core losses versus $B_{\max }$ at the frequency of $20 \mathrm{kHz}$ for the Ni-Fe and $\mathrm{Ni}-\mathrm{Fe}-\mathrm{Mo}$ samples

Table 1 Magnetic properties of the prepared materials

\begin{tabular}{|c|c|c|}
\hline & Ni-Fe & Ni-Fe-Mo \\
\hline DC coercivity & $11 \mathrm{~A} / \mathrm{m}$ & $11,2 \mathrm{~A} / \mathrm{m}$ \\
\hline $\begin{array}{c}\text { Losses at } \\
\mathbf{f = 1 0 k H z}, \\
\mathbf{B}_{\max }=\mathbf{0}, \mathbf{2 T}\end{array}$ & $1,8 \mathrm{~W} / \mathrm{g}$ & $1,4 \mathrm{~W} / \mathrm{g}$ \\
\hline $\begin{array}{c}\text { Losses at } \\
\mathbf{f = 1 M H z} \\
\mathbf{B}_{\max }=\mathbf{0 , 0 2 T}\end{array}$ & $14 \mathrm{~W} / \mathrm{g}$ & $11 \mathrm{~W} / \mathrm{g}$ \\
\hline $\begin{array}{c}\text { Peak } \\
\text { permeability at } \\
\mathbf{f = 1 0 k H z ,} \\
\mathbf{B}_{\text {max }}=\mathbf{0}, \mathbf{2 T}\end{array}$ & 50 & 84 \\
\hline
\end{tabular}

\section{CONCLUSIONS}

The soft magnetic properties of the $\mathrm{Ni}_{81} \mathrm{Fe}_{19}$ and $\mathrm{Ni}_{79} \mathrm{Fe}_{16} \mathrm{Mo}_{5}$ alloys have been investigated. From the above study, we conclude that the magnetic properties of the permalloys and supermalloys (a metal alloy that is $79 \%$ nickel, 5\% molybdenum and 16\% iron) show strong conditions. The bulk sample $\mathrm{Ni}_{79} \mathrm{Fe}_{16} \mathrm{Mo}_{5}$ is found to show better soft magnetic properties over the $\mathrm{Ni}_{81} \mathrm{Fe}_{19}$ bulk sample as a function of different process parameters. We prepared bulk samples in the form of the small cylinders with coercivity down to $11 \mathrm{~A} / \mathrm{m}$. The discussed alloys show very good soft magnetic properties that can be tailored to the need of certain requirements by adjusting chemical composition, the processing routes such as compaction, and heat treatment conditions. They have more degrees of freedom for tailoring their magnetic and dimensions.

Therefore, to achieve very good soft magnetic properties of compacted-powder bulk materials, it is of the total core losses.

\section{ACKNOWLEDGMENTS}

This work was realized within the frame of the project The progressive technology for preparation of microcomposite materials for electrotechnology MIKROMATEL, ITMS 26220220105 and The centre of excellence of progressive materials with micro and submicron structure ITMS 2622012001, which is/was supported by the Operational Program "Research and Development” financed through European Regiona Development Fund. This work was also supported by the Slovak Research and Development Agency under the contract No. APVV-0222-10 MAGCOMP and by the Agency of the Ministry of Education of Slovak Republic and the Slovak Academy of Sciences, project No. VEGA 1/0861/12 and No. 1/0862/12.

\section{REFERENCES}

[1] ARNOLD, H. D. - ELMER, G. W.: J. Frank Inst., vol. 195, pp. 621, 1923.

[2] SURYANARAYANA, C.: Prog. Mater. Sci. vol. 46, no. 1, 2001.

[3] KALOSHKIN, S. D. - TCHERDYNTSEV, I. A., TOMILIN, I. A. - BALDOKHIN, Yu. V. SHELEKHOV, E. V.: Physica B, vol. 299, pp. 236, 2001.

[4] ISNARD, O. - POP, V. - CHICINAS, I.: Journal of magnetism and Magnetic Materials, vol. 290-291, pp. 1535, 2005.

[5] FÜZER, J. - KOLLÁR, P. - OLEKŠÁKOVÁ, D. ROTH, S.: Journal of Alloys and Compounds, vol. 483, pp. 557-559, 2009.

[6] KOLLÁR, P. -, OLEKŠÁKOVÁ, D. - FÜZER, J. KOVÁC̆, J. - ROTH, S. - POLANSKI, K.: Journal 
of magnetism and Magnetic Materials, vol. 310, pp. 2609-2611, 2007.

[7] FÜZER, J. - KOLLÁR, P. - OLEKŠÁKOVÁ, D. ROTH, S.: Acta Physica Polonica A, vol. 113, no. 1, pp. 59-62, 2008.

[8] OLEKŠÁKOVÁ, D. - ROTH, S. - KOLLÁR, P. FÜZER, J.: Journal of magnetism and Magnetic Materials, vol. 304, pp. 730, 2006.

[9] KRONMULLER, H. - PARKIN, S.: Handbook of Magnetism and Advanced Magnetic Materials, Volume 2- Micromagnetism, Wiley, New York, 2007.

[9] KIM, Y. B. - KIM, K. Y.: IEEE Transactions on Magnetics, vol. 42, No. 10, pp. 2802-2805, 2006.

[10] KIM, D. - OHNISHI, M. - MATSUSHITA, N. ABE, M.: IEEE Transactions on Magnetics, vol. 39, No. 5, pp. 3181-3183, 2003.

Received November 27, 2012 , accepted February 9, 2013

\section{BIOGRAPHIES}

Denisa Olekšáková was born on 20.08.1979. In 2002 she graduated (MSc) of the Faculty of Science at P. J. Šafárik University in Košice. She defended his $\mathrm{PhD}$ in the field of magnetic properties of the crystalline materials in the bulk, powder and ribbon forms in 2007. Her thesis title was "Soft magnetic materials based on FeNi“. Since 2007 she is working at Department of Applied Mathematics and Informatics at the Technical University in Košice. Her scientific research is focusing on magnetic properties of soft magnetic materials.

Ján Füzer was born on 22.01.1971. In 1994 he graduated (MSc) with distinction at the department of Solid state physics of the Faculty of Science at P. J. Šafárik University in Košice. He defended his PhD in the field of magnetic properties of the amorphous and nanocrystalline materials in the bulk, powder and ribbon forms; his thesis title was "The study of the magnetic properties of the soft magnetic materials". Since 1997 he is working as a scientist with Institute of Physics at the same University. His scientific research is focusing on electrical and magnetic properties of soft magnetic materials. In addition, he also investigates the structure influence on the magnetic losses and complex permeability of ferromagnetic materials.

Peter Kollár was born on 23.04.1960. In 1987 he graduated (MSc) with distinction at the department of Experimental physics of the Faculty of Science at P. J. Šafárik University in Košice. He defended his PhD in the field of magnetic properties of the amorphous materials in the form of ribbon, his thesis title was "Surface magnetic properties of FeB based amorphous alloys“. Since 2009 he is working as a professor with Institute of Physics at the same University. His scientific research is focusing on magnetic properties of soft magnetic materials. 